\title{
Cardiff Crohn's disease jubilee: the incidence over 50 years
}

\author{
J D R ROSE, G M ROBERTS, G WILLIAMS, J F MAYBERRY, \\ AND J RHODES
}

From the Departments of Gastroenterology, Radiology and Pathology, University Hospital of Wales, Cardiff, and Department of Medicine, City Hospital, Nottingham

SUMmary The incidence of Crohn's disease in Cardiff between 1931 and 1985 has been examined using hospital diagnostic indices supplemented in recent years by records from clinicians, and the departments of pathology and radiology. Four hundred and seven new patients were confirmed after all notes had been reviewed. There has been a large increase from $0 \cdot 18$ cases/10 $/ 1$ of the population per year in the 1930 s to current values of $8 \cdot 3 / 10^{5} /$ year. The incidence continues to rise and shows an increasing proportion of patients with colorectal disease. Peak age specific incidences occur in the third and eighth decades of life.

It is more than 50 years since Burrill Crohn described the disease which bears his name' but Dalziel's prediction which was made 20 years earlier 'that further consideration would clear up the difficulty about aetiology' remains unfulfilled. ${ }^{2}$ The incidence of the disease has risen steeply in the western world since the 1930s and this cannot be entirely attributed to increased recognition of the disease (Fig. 1, Table 1). Details of new cases and the incidence of Crohn's disease in the City of Cardiff have previously been reported $^{34}$ and we now present more than 50 years of data collected between 1931 and 1985, which represents the longest continuous study of this disease.

\section{Methods}

PATIENTS

We identified patients with Crohn's disease from a diagnostic index of hospital inpatients which had been kept since 1926 and which had been computerised for the last 20 years. Outpatients were identified from diagnostic indices of gastrointestinal clinics and the Departments of Pathology and Radiology. Recent data from the last five years were collected in a manner identical to that used in previous work from Cardiff. ${ }^{34}$ Patients were considered if they were resident in the City of Cardiff at the time of diagnosis, and were accepted into the

Address for correspondence: Professor John Rhodes, University Hospital of Wales, Heath Park, Cardiff CF4 4XW.

Received for publication 24 September 1987. study if there was histological evidence of Crohn's disease from a biopsy or resected specimen, or alternatively if there was radiological evidence with a clinical history compatible with the disease. All

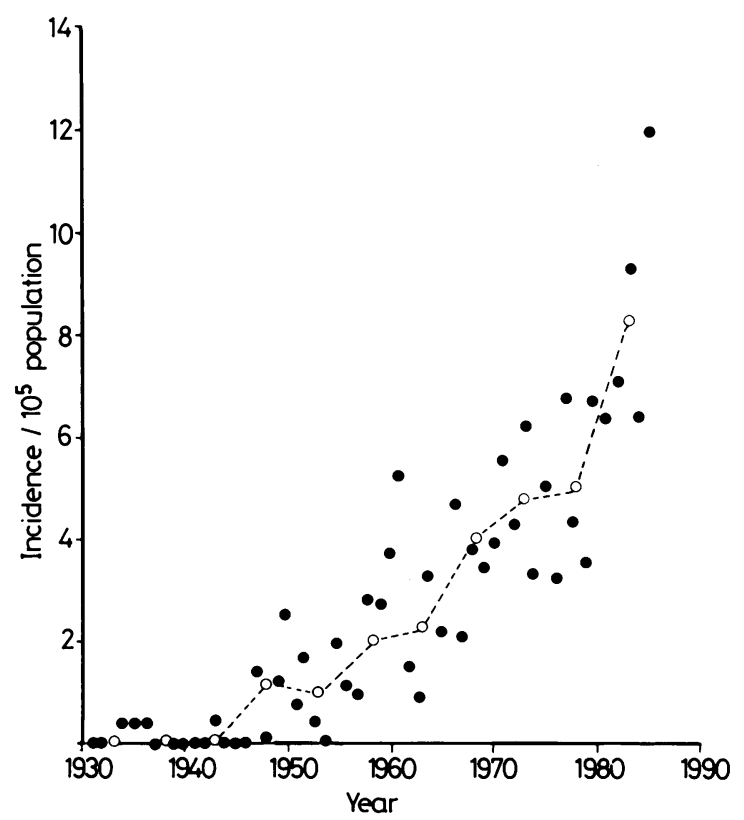

Fig. 1 Yearly incidence of new cases of Crohn's disease in Cardiff between 1931 and $1985(n=407), 0 \cdots 0$ mean incidence for each five year period. 
Table 1 Incidence of Crohn's disease by quinquennium from 1931-1985. Statistical comparison by techniques described by Fleiss ${ }^{16}$

\begin{tabular}{|c|c|c|c|c|}
\hline $\begin{array}{l}\text { Time } \\
\text { interval }\end{array}$ & $\begin{array}{l}\text { Patients } \\
\text { (n) }\end{array}$ & $\begin{array}{l}\text { Total } \\
\text { population } \\
\times 10^{5}\end{array}$ & Incidence $/ 10^{5}$ & $\begin{array}{l}95 \% \\
\text { limits }\end{array}$ \\
\hline $1931-1935$ & 3 & $2 \cdot 21$ & 0.3 & $0.09-0.9$ \\
\hline $1936-1940$ & 2 & $2 \cdot 23$ & $0 \cdot 2$ & $0.09-0.7$ \\
\hline $1941-1945$ & $1)$ & $2 \cdot 22$ & $0 \cdot 1$ & $0-0.6$ \\
\hline 1946-1950 & 15 & $2 \cdot 40$ & $1 \cdot 3$ & $0 \cdot 8-2 \cdot 1$ \\
\hline $1951-1955$ & 12 & $2 \cdot 46$ & 0.9 & $0.5-1.8$ \\
\hline $1956-1960$ & $26\}$ & $2 \cdot 53$ & $2 \cdot 1$ & $1 \cdot 4-3 \cdot 1$ \\
\hline $1961-1965$ & $33\}$ & $2 \cdot 8$ & $2 \cdot 3$ & $1 \cdot 6-3 \cdot 4$ \\
\hline $1966-1970$ & $57\}$ & $2 \cdot 81$ & $4 \cdot 0$ & $3 \cdot 1-5 \cdot 3$ \\
\hline $1971-1975$ & 69 & $2 \cdot 85$ & $4 \cdot 8$ & $3 \cdot 8-6 \cdot 2$ \\
\hline $1976-1980$ & 72 & $2 \cdot 81$ & $5 \cdot 0$ & $4-6.5$ \\
\hline $1981-1985$ & $117\}$ & $2 \cdot 79$ & $8 \cdot 3$ & $-10 \cdot 1$ \\
\hline
\end{tabular}

${ }^{*} \mathrm{p}<0 \cdot 005 ; \dagger \mathrm{p}<0 \cdot 05$.

patients notes were examined and cases without clear evidence of Crohn's disease were not accepted.

The name, address, date of birth, age at diagnosis, method of diagnosis and initial distribution of disease were recorded. The distribution of disease was defined as follows: (1) Terminal ileum refers to disease which may include radiological distortion of the caecum, but excludes patients with more distal
Table 2 Distribution of disease in 407 patients. The categories are mutually exclusive and 'terminal ileum' only refers to ileal involvement alone. 'Mixed' refers to patients with both colonic and small bowel involvement. 'Small bowel' refers to those with extensive small bowel disease

\begin{tabular}{lcc}
\hline Site & $\begin{array}{l}\text { Patients } \\
(n)\end{array}$ & $\begin{array}{l}\text { Percentage of } \\
\text { totals }\end{array}$ \\
\hline Terminal ileum only & 182 & 45 \\
Colorectal & 119 & 29 \\
'Mixed' (colon + ileum or & 51 & 13 \\
$\quad$ jejunum) & & 6 \\
Small bowel & 25 & 2 \\
Anus & 9 & 5 \\
Other & 21 & 100 \\
& 407 & \\
\hline
\end{tabular}

colonic involvement; this corresponds with our previous category of ileocaecal disease. (2) 'Mixed' refers to involvement of the colon with either ileum or jejunum, in our previous papers referred to as extensive disease. (3) Colorectal disease is disease of the large bowel only.

The Registrar General's midyear estimates for the population of Cardiff with its age and sex structure were used to calculate incidence and age specific incidence.

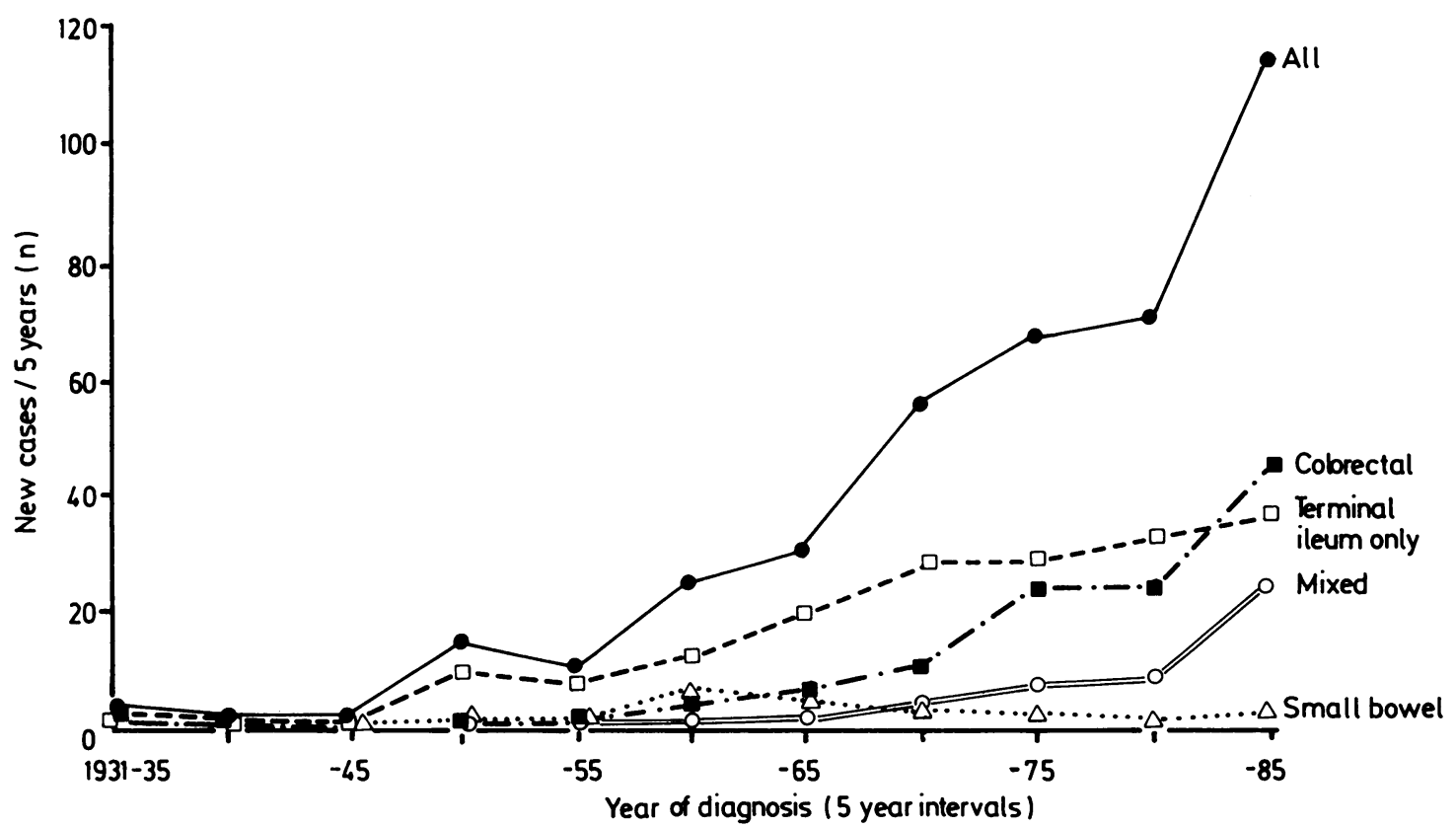

Fig. 2 Number of new cases with disease of different sites presenting during each five year period from 1931 to 1985. Colorectal disease is limited to this site and 'terminal ileum' only refers to disease without colonic involvement distal to the caecum. 'Mixed' refers to involvement of colon with ileum or jejunum and 'small bowel' to extensive small bowel involvement only. 


\section{Results}

Four hundred and seven new patients, 171 men and 236 women were identified between 1931 and 1985 . When corrected for the greater number of women in Cardiff the male:female ratio is $1: 1.29 \quad(z=2.4$, $\mathrm{p}<0.02$, Fleiss, 1981). The incidence each quinquennium rose from $0 \cdot 3 / 10^{5} /$ year between 1931 and 1935 to $8 \cdot 3 / 10 \%$ year between 1981 and 1985 . There was great variation from year to year but the five year figures show a consistent increase with no tendency to plateau. The proportion of patients diagnosed by laparotomy has declined steadily from $100 \%$ between 1931 and 1945 , but in the last 10 years has remained constant at $25 \%$

At the time of diagnosis in 239 of the patients $(59 \%)$ the ileum was involved, but only 182 patients had disease which appeared limited to the terminal ileum only. Other sites which were involved when patients were first diagnosed were the left half of the colon in 115 , the right colon in 62 , rectum in 51 , the anus in 53 , small bowel in 46 , the gastroduodenal region in five and three with oral disease. Over the period of the study the ileum has consistently been the most common site involved although there has been a steady rise in the number of patients with both colorectal and mixed colonic with small intestinal involvement (Fig. 2). The most recent figures show a similar incidence for ileum alone and colorectal disease. The numbers with diffuse small bowel and anal involvement only have shown little change. Patients have also been grouped according to distribution of disease as more than one site is often involved (Table 2). The three most common patterns of distribution were ileum alone $(45 \%)$, colon and rectum $(29 \%)$ and colon with ileum or jejunum 'mixed' disease $(13 \%)$. We were uncertain whether the right colon was affected in $13 \%$ of patients and information was incomplete about rectal involvement in $6 \%$ of patients.

The largest group of patients present between 15 and 30 years of age (Fig. 3). The age specific incidence is calculated for three separate periods of the study in Figure 4. High figures for incidence are seen in both the younger (15-29 years) and older (6574 years) age groups and figures from each phase of

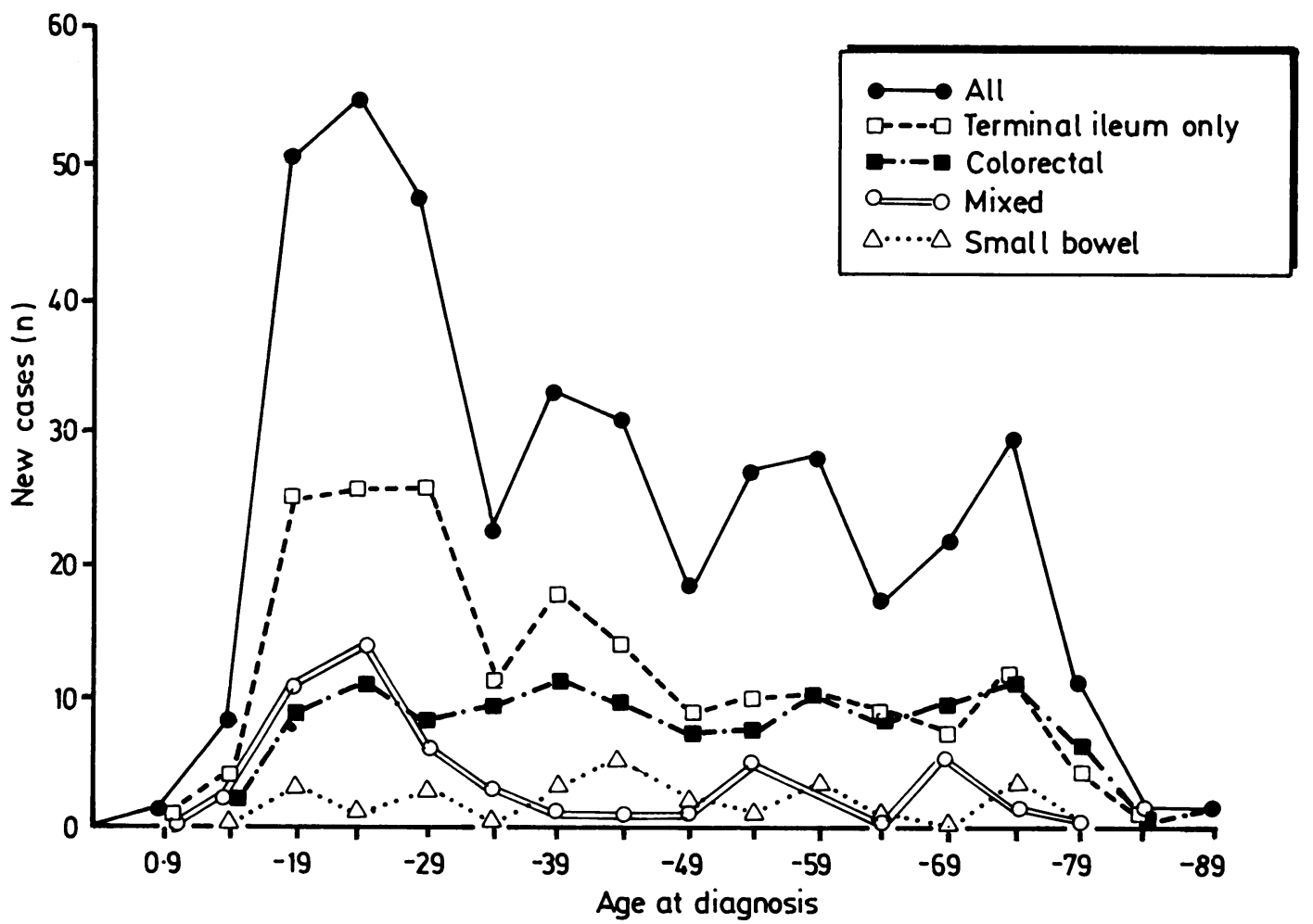

Fig. 3 Number of cases presenting between 1931 to 1985 analysed according to the patient's age and the initial site of disease. 'Terminal ileal' only refers to patients with terminal ileal involvement only which may include distortion of the caecum. 'Mixed' refers to the presence of both colonic with small bowel disease. 'Small bowel' refers to patients with extensive small bowel disease only. 


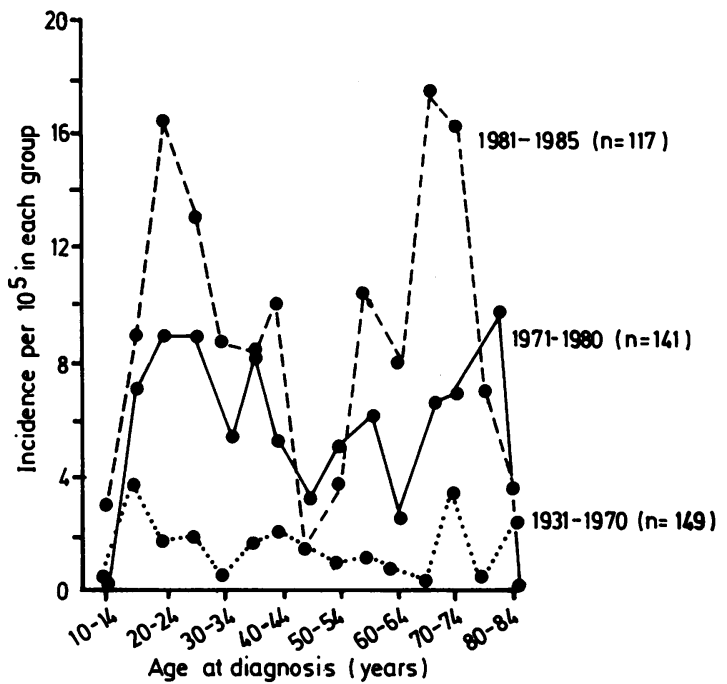

Fig. 4 Incidence of new cases in each age group for the periods 1931-1970, 1971-1980 and 1981-1985. Age structure of Cardiff's population was derived from census figures for the years 1951, 1975 and 1983. Incidence of disease in the 20-24 year age group diagnosed between 1981 and 1985, and the 70-74 year age group was significantly greater than in the 40-44 age group ( $z=3 \cdot 4$ in each case, $p<0 \cdot 001$ Fleiss, 1981$)$.

the study show a consistent trend with distinguishable peaks for the 1981-85 period.

The distribution of disease according to the age of onset is in Figure 3. Although ileum was involved in three-quarters of the patients diagnosed between the ages of 15 and 24, this figure falls to less than half for those over 55 years of age. By contrast, the proportion of patients with colorectal disease increases from $19 \%$ in younger patients to $41 \%$ in those over 55 years of age.

The initial diagnosis was made by laparotomy in $44.5 \%$ of the whole group, but for those with extensive small bowel or ileal disease the figures were $72 \%$ and $62 \%$ respectively. In patients with large bowel disease laparotomy was used less often (15\%). Before 1970 the male to female ratio was 1:2 but has changed so that men and women are now equally affected; this change applies to all three major distributions of disease (Table 3).

\section{Discussion}

This study of Crohn's disease over 55 years has shown a continuous rise in the incidence to current values of about $8 / 10^{5}$ of the population and does not agree with an earlier suggestion that a plateau may have been reached. ${ }^{4}$ During this period several changes have taken place which include an increase in colorectal disease, and a move towards equal involvement of
Table 3 Sex ratio of patients for three periods of the study from 1931 to 1985 showing the ratio for all patients in each of the four periods, with numbers of patients given in parentheses. The ratios and total number of patients involved are given for three separate sites-terminal ileum only, colorectal and mixed - colonic with small intestinal disease

\begin{tabular}{llllll}
\hline Time interval & \multicolumn{5}{l}{ Disease site } \\
\cline { 1 - 1 } \cline { 5 - 6 } & $\begin{array}{l}\text { All } \\
\text { patients }\end{array}$ & $\begin{array}{l}\text { Terminal } \\
\text { ileumonly }\end{array}$ & Colorectal & Mixed \\
\hline $1931-1970$ & $2 \cdot 0(149)$ & $2 \cdot 5(85)$ & $5 \cdot 2(25)$ & $1 \cdot 3(9)$ \\
$1971-1980$ & $1 \cdot 2(141)$ & $1 \cdot 3(60)$ & $1 \cdot 9(49)$ & $0 \cdot 9(17)$ \\
$1981-1985$ & $1 \cdot 0(117)$ & $1 \cdot 2(37)$ & $0 \cdot 9(45)$ & $0 \cdot 9(25)$ \\
\hline
\end{tabular}

both sexes. During the period 1981 to 1985 , for the first time colorectal disease became the most common distribution of disease at the time of presentation. Although most patients present with the disease as young adults, age specific incidence figures show a second peak suggesting that it is equally common in the elderly. These two peaks which occurred in the third and eighth decade were present at each of the three stages of the study (Fig. 4). Such findings do not support the proposition that a cohort with high risk of Crohn's disease is present, aging and responsible for the rising incidence in elderly patients. ${ }^{5}$ The overall female preponderance has changed in the last 15 years with figures which now approach equality for the sexes.

Longterm studies on the incidence of disease inevitably raise questions about validity. The methods used to collect data in Cardiff, however, have not changed since our first study. ${ }^{3}$ The criteria and methods used for diagnosis have remained the same and all patients notes were reviewed to confirm the diagnosis. Criticism that the rise in incidence is attributable to less severe disease is not supported by the continued increase in terminal ileal disease which has clear radiological features which are seldom misdiagnosed. In addition, the number of laparotomies for severe disease continued to rise until 15 years ago; since then the percentage of patients submitted to laparotomy has remained unchanged despite larger numbers of patients being diagnosed. A decline in this percentage would have been expected if numbers had been artifactually boosted by more patients with mild disease. Over recent years more reliance has been placed on radiology and laparotomy has been restricted to patients requiring surgical resection. Patients with disease limited to the colon would have been excluded from most groups of Crohn's disease 25 years ago and our figures certainly show a significant rise in this 


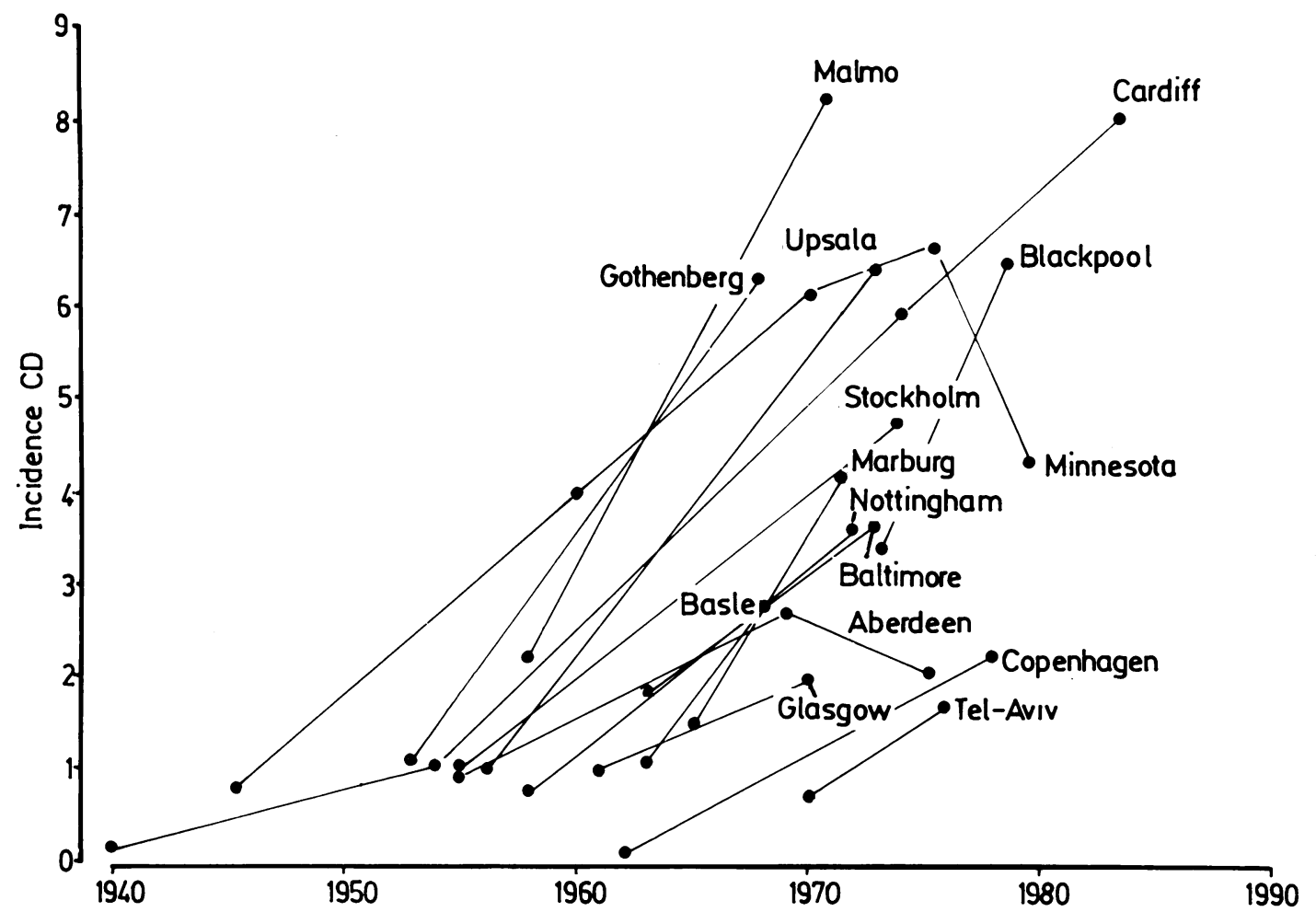

Fig. 5 Changes in the incidence of Crohn's disease in recent decades in various geographical areas. Initial and most recent figures are given with occasional intermediate figures.

form of disease in recent years. This can only account, however, for part of the observed rise in incidence. The persistent increase in ileal disease and the continuing use of laparotomy in diagnosis suggest that the rise is not artifactual, although its magnitude may be influenced by various factors.

The rise in incidence is striking, and more than five-fold over the last 50 years. Similar changes have been observed in other centres in the western world where the highest reported incidences have been similar. ${ }^{568.12}$ (Fig. 5) Heller in Stockholm ${ }^{56}$ felt that his data were consistent with a cohort of people at high risk of developing the disease, but this hypothesis is not supported by our data because the two peaks for age specific incidence in the third and eighth decade were observed at each stage of the survey (Fig. 4). We found a preponderance of female patients which is consistent with most reports but recent figures from Cardiff suggest a change approaching unity similar to Heller's observations. ${ }^{56}$ This change in the sex ratio . during the last 50 years appears to be real as the ratio in the general population has remained about 1.08 throughout the study. The increasing number of elderly patients would favour an excess of women in the total numbers; these factors would suggest that the observed change in sex ratio is unlikely to be a consequence of some distortion in the age distribution of disease. In addition the suggestion that the increased incidence of Crohn's disease may be because of use of the contraceptive pill by younger women $^{1+15}$ is not supported by our data.

In the absence of any major progress on the cause or curative treatment for Crohn's disease, the prospect of increasing numbers of patients with this chronic and often debilitating illness is daunting.

\section{References}

1 Crohn BB, Ginzberg L, Oppenheimer GD. Regional ileitis; a pathological and clinical entity. J Am Med Ass 1932; 99: 1323-7.

2 Dalziel TK. Chronic interstitial enteritis. Br Med J 1913; 2: 1068-70.

3 Mayberry JF, Rhodes J, Hughes LE. Incidence of Crohn's disease in Cardiff between 1934 and 1977. Gut 1979; 20: 602-8.

4 Harries AD, Baird A, Rhodes J, Mayberry JF. Has the incidence of Crohn's disease reached a plateau? $\mathrm{Br} \mathrm{Med}$ J 1982; 284: 235. 
5 Hellers GKG. Crohn's disease in Stockholm County 1955-74: a study of epidemiology, results of surgical treatment and long-term prognosis. Acta Chir Scand 1979; 90: 1-84.

6 Hellers G. Crohn's disease in Stockholm County. In: Lee ECG. ed. A Global Assessment of Crohn's Disease. Crohn's Workshop. London: Heyden HM \& M: 85-91.

7 Mayberry JF, Rhodes J. Epidemiological aspects of Crohn's disease: a review of the literature. Gut 1984; 25: 886-9.

8 Miller DS, Keighley AM, Langman MJS. Changing patterns in epidemiology of Crohn's disease. Lancet 1974; ii: 691-3.

9 Kyle J. An epidemiological study of Crohn's disease in North-East Scotland. Gastroenterology 1971; 61: 826-33.

10 Kyle J, Stark G. Fall in the incidence of Crohn's disease. Gut 1980; 21: 340-3.

11 Brahme F, Lindstrom C, Wenckert A. Crohn's disease in a defined population. An epidemiological study of incidence, prevelance, mortality and secular trends in the City of Malmo, Sweden. Gastroenterology 1975; 69: $342-57$.

12 Riis P, Binder V. Epidemiological data of chronic inflammatory bowel diseases in the Copenhagen region. In: McConnell R, ed. The genetics and epidemiology of inflammatory bowel disease. Basel: Karger, $1986 ; 42-53$.

13 Gilat T, Langman MJS, Rozen P. Environmental factors in inflammatory bowel disease. In: McConnell $\mathrm{R}$, ed. The genetics and epidemiology of inflammatory bowel disease. Basel: Karger, 1986; 158-76.

14 Rhodes JM, Cockel R, Allan RN, Hawker PC, Dawsin J, Elias E. Colonic Crohn's disease and use of oral contraception. Br Med J 1984; 288: 595-6.

15 Lesko SM. Kaufman DW, Rosenberg L, et al. Evidence for an increased risk of Crohn's disease in contraceptive users. Gastroenterology 1985; 89: 1045-9.

16 Fleiss J. Statistical methods for rates and proportions. 2nd ed. New York: Wiley, 1981: 14-15, 29-30. 